\title{
Pattern of Skin disorders across age groups
}

\author{
*Ayanlowo $0 .^{1,2}$ Okesola $0 .^{2}$
}

\begin{abstract}
Objective: Pattern of skin diseases has been noted to differ across age groups both in specific types and in clinical manifestations. This variation across age groups has been attributed to growth and development of the skin; to complex hormonal changes occurring at different stages of life; and environmental factors. To highlight differences in the pattern of presentation of skin disorders in different age groups with respect to the characteristic physiological changes in patients seen at the Lagos University Teaching Hospital.
\end{abstract}

Methods: This is a retrospective cross-sectional study done at the dermatology clinic. Demographic data and diagnoses were extracted from the clinical records of all new patients seen between January 2010 and December 2014 (a five year period). These were captured on Microsoft Excel spreadsheet and analyzed using SPSS 21.

Results: Infections and eczematous conditions were the most prominent group(s) of cutaneous disorders across all ages though acne vulgaris ranked high in adolescents/young adults. Nutritional dermatoses, infestations and genetic disorders occurred predominantly in the pediatric age group. All other diseases peaked in the adult group whilst infections, eczemas and papulosquamous disorders had two peaks (in the pediatric and the adult age group).

Conclusion: Infections and eczematous condition were the most prominent group of cutaneous disorder across all ages apart from acne vulgaris which ranked high in the adolescents/young adults. Knowledge of this will help in health planning and early diagnosis of skin disorders.

Keywords: Skin, Age Groups, Infections, Eczemas, Acne vulgaris

*Corresponding author: Dr Ayanlowo O. Email: solayan05@yahoo.com;

'Department of Medicine, Faculty of Clinical Sciences, College of Medicine, University of Lagos

${ }^{2}$ Department of Medicine, Lagos University Teaching Hospital, Lagos

Research Journal of Health Sciences subscribed to terms and conditions of Open Access publication. Articles are distributed under the terms of Creative Commons Licence (CC BY-NC-ND 4.0). (http://creativecommons.org/licences/by-nc-nd/4.0).

http://dx.doi.org/10.4314/rejhs.v5i3.4 


\title{
Motif des troubles cutanés chez les groupes d'âge
}

\author{
*Ayanlowo O. ${ }^{1,2}$ Okesola O.
}

\begin{abstract}
Resume
Objectif: Il a été observé que le profil des maladies de la peau diffère selon les groupes d'âge, à la fois dans des types spécifiques et dans des manifestations cliniques. Cette variation entre les groupes d'âge a été attribuée à la croissance et au développement de la peau; aux changements hormonaux complexes se produisant à différents stades de la vie; et les facteurs environnementaux. Pour mettre en évidence les différences dans le modèle de présentation des troubles de la peau dans différents groupes d'âge en ce qui concerne les changements physiologiques caractéristiques chez les patients vus à l'hôpital universitaire de Lagos.
\end{abstract}

Méthode: Il s'agit d'une étude transversale rétrospective réalisée à la clinique de dermatologie. Les données démographiques et les diagnostics ont été extraits des dossiers cliniques de tous les nouveaux patients entre janvier 2010 et décembre 2014 (période de cinq ans). Ceux-ci ont été capturés sur une feuille de calcul Microsoft Excel et analysés à l'aide de SPSS 21.

Résultats: Les infections et les affections eczémateuses constituaient le groupe le plus important de troubles cutanés à tous les âges, bien que l'acné vulgaire ait un rang élevé chez les adolescents et les jeunes adultes. Les dermatoses nutritionnelles, les infestations et les troubles génétiques sont survenus principalement dans le groupe d'âge pédiatrique. Toutes les autres maladies ont atteint un sommet dans le groupe des adultes alors que les infections, les eczémas et les troubles papulo-squameux ont connu deux pics (chez les enfants et les adultes).

Conclusion: Les infections et les affections eczémateuses constituaient le groupe le plus important de troubles cutanés à tous les âges, à l'exception de l'acné vulgaire, qui occupait une place importante chez les adolescents et les jeunes adultes. La connaissance de ceci aidera dans la planification de santé et le diagnostic tôt des désordres de peau.

Mots-clés: Peau, Groupes d'âge, Infections, Eczémas, Acné vulgaire

*Auteur correspondant: Ayanlowo O.; Email: solayan05@yahoo.com;

'Department of Medicine, Faculty of Clinical Sciences, College of Medicine, University of Lagos

${ }^{2}$ Department of Medicine, Lagos University Teaching Hospital, Lagos

Research Journal of Health Sciences subscribed to terms and conditions of Open Access publication. Articles are distributed under the terms of Creative Commons Licence (CC BY-NC-ND 4.0). (http://creativecommons.org/licences/by-nc-nd/4.0).

http://dx.doi.org/10.4314/rejhs.v5i3.4 


\section{INTRODUCTION}

Pattern of skin diseases has been noted to differ across age groups both in specific types and in clinical manifestations as far back as the $19^{\text {th }}$ century (1). This variation across age groups has been attributed to growth and development of the skin and to complex hormonal changes occurring at different stages of life.

Skin development is a continuous process, beginning during intrauterine life and continuing through infancy. At birth, the skin contains all the anatomical structures present in adult skin but is functionally immature (2). However, infants have smaller corneocytes and a significantly thinner stratum corneum which persists until 2 years of age (3). The skin of newborns also contain fewer fibrils at the dermoepithelial junction and decreased dermal collagen deposits when compared to adults thereby making it more trauma prone (3).

The functional impairment seen in infants due to the anatomical differences earlier highlighted include increased trans epidermal water loss; impaired skin hydration and acidity; and low activity of the sebaceous gland which ultimately compromise the barrier functions of the skin (4-6). Impaired skin barrier function seen in infants and to a less extent in childhood increases the risk of dermatoses such as atopic dermatitis, contact dermatitis, and skin infections $(7,8)$. In the school age, there is increasing contact with the environment and various contagions which make them more susceptible to infections (9-12).

Puberty can herald the onset of new skin diseases such as seborrheic dermatitis, acne vulgaris, pityriasis versicolor, Fox-Fordyce disease, and hidradenitis suppuritiva, as a result of increased sebum production and activity of the apocrine glands (13). These dermatoses especially acne which occur on the face results in psychological disturbance in this age group (14). Dermatophyte infections particularly of the scalp with high prevalence in childhood resolve spontaneously or become rare in adolescent as a result of the fungistatic effect of the fatty acids contained in the sebum (15).

Skin disorders in the elderly occur as a consequence of the interplay of many factors including alteration in structure and function of the ageing skin; cumulative effects of exposure of various environmental insults such as ultraviolet radiation (UVR); cutaneous consequences of ageing and age related diseases in other organ systems; increasing leisure; and continued exposure to potential irritants and sensitizers (1618).

This work aims to highlight differences in the pattern of presentation of skin disorders in different age groups with respect to the characteristic physiological changes in patients seen at the Lagos University Teaching Hospital. The knowledge of pattern of skin disorders in different age groups will be useful in differential diagnoses, early and prompt management as well as inform the allocation of health resources in the resource limited setting.

\section{MATERIALS AND METHODS}

This is a retrospective cross-sectional study. The study site was the Lagos University Teaching Hospital (LUTH), situated in Lagos state in South Western Nigeria. The Lagos University Teaching Hospital (LUTH) is located in Mushin local government area of Lagos state. It occupies 92 acres of land and has over 700 bed facility, making it one of the largest teaching hospitals in Nigeria. The Dermatology Unit of LUTH runs thrice weekly clinics: Fridays for new cases, Mondays for follow-up of cases, and Tuesdays for genitourinary medicine (venereology) and rheumatology clinics and dermatology procedures. The Dermatology Clinic of LUTH has an average weekly clinic attendance of about one hundred and eighty-five (60 new, 100 old and 25 procedures) patients who are from virtually all the major tribes in Nigeria.

Study participants were all new patients seen at the dermatology clinic between January 2010 and December 2014 (a five year period). Patients of all ages seen at the dermatology clinic between January, 2010 and December, 2014 were included. Participants with inconclusive diagnosis were excluded from the study.

Approval was obtained from the Ethical Committee of the Lagos University Teaching Hospital before the commencement of the study. Data was retrieved from patient's clinic notes and hospital records which included patients' age, sex, and diagnoses.

The data was captured on Microsoft Excel spreadsheet. Analysis was done using SPSS 21. Descriptive statistics were done and results were summarised with tables, graphs and charts.

\section{RESULTS}

A total of 10,865 patients were seen over the study period There was a female preponderance; with 4801 males $(44.2 \%)$ and 
6064 females (55.8\%). The mean age at presentation was $28.97 \pm 17.9$. The youngest patient was 6 weeks while the oldest was 95 years of age. Data of 20 patients were excluded because their ages were not documented. The frequency of patients in the paediatric age group ( 0 to 15 years) was $2768(25.5 \%)$; young adult group (16 to 25$)$ was $2034(18.8 \%)$; in older adults (26 to 44) was 3968 (36.6\%); in the middle age group (45 to 64 ) was $1636(15.1 \%)$, and in the elderly group (65 and above) was 439 (4.0\%) (Figure 1).

Overall, across all age groups, five most prominent skin conditions were infections, eczemas, pruritus, acne and papulosquamous in descending order, apart from the young adult (1625 ) in whom acne and infections ranked first. These together accounted for about two thirds of skin disorders in all age groups. The five most common dermatoses in the paediatric age group (0-15) are infections, eczemas, infestations, papulosquamous and pigmentary disorders. In the young adult (16-25), acne and infections were the predominant skin conditions followed by eczemas, pruritic dermatoses and papulosquamous disorders. In older adult (2644), infections were predominant followed by eczemas, pruritic dermatoses, acne and papulosquamous disorders. In the middle age group (45-65), infections were the most predominant, followed by pruritus, eczemas, papulosquamous and pigmentary disorders. In the elderly, infections were the most predominant followed by eczemas, pruritus, pigmentary and papulosquamous disorders. (Table 1) Tables two to six further sub classify various common disease groups and show their frequencies.

Acne vulgaris was found in 981 patients while rosacea was in 18 patients. Types of drug eruption seen include fixed drug eruptions in 187 patients $(85.8 \%)$, non specific drug reactions such as drug exanthema and pruritus in 19 patients, Steven Johnson syndrome in 5, lichenoid drug eruptions in 4 and phototoxicity in 3. Different types of ulcers were diagnosed in 57 patients and this include chronic leg ulcers in 27, stasis ulcer in 10 patients, pyoderma gangrenosum in 5, genital ulcers in 4 and aphthous ulcer in one. Psychocutaneous disorders was diagnosed in 30 patients and this include somatisation in $18(60 \%)$; abnormal perception of body odour in $9(30 \%)$; trichotillomania in 3 and delusion of parasitosis in one patient. Disorders of abnormal scar formation were found in 479 patients and these included keloid in 439 (91.6\%), hypertrophic scars in $28(5.8 \%)$ and atrophoderma in 5.

Pyogenic granuloma accounted for $38 \%$ (41 patients) of all granulomas seen while granuloma annulare, erythema nodosum, sarcoidosis and foreign body granulomas were diagnosed in 33 (30.6\%), 24 (22.2\%), 9 (8.3\%) and $1(0.9 \%)$ respectively. Eighty patients presented with lymphoedema and 3 with generalized lymphadenopathy. Phrynoderma, a nutritional dermatosis associated with vitamin A deficiency was found in 28 children.

Certain disorders were classed as miscellaneous as they could not fit into any of the groups and this include subcutaneous nodules 19, peripheral neuropathies 17 , cysts 16 , postherpetic neuralgia 14 , palmoplantar keratoderma 12 , nail diseases 11 , hydradenitis suppurativa 8 , striae distensae 8, diabetes mellitus associated skin conditions 7 , hyperhidrosis 7 , Callus 5 , pedal oedema 4 , varicose vein 3 , vagina discharge 2 , amyloidosis 1 , Fox fordyce disease 1 and pearly penile papule 1 .

\section{DISCUSSION}

Across all ages, infectious diseases were the most frequently seen dermatoses similar to findings in previous studies in Nigeria and other African countries, although there is evidence to suggest increasing prevalence of eczematous conditions (19-22). Factors noted to be responsible for the high prevalence of infectious disorders include poor socioeconomic status, low literacy levels, hot humid climate, poor hygiene, overcrowding and high interpersonal contact $(22,23)$. In Jos, Nigeria, eczematous skin diseases were the most prevalent skin disorders (26.5\%) at their clinic. (24) Across the country, there has been a gradual increase in prevalence of atopic dermatitis: $<0.3 \%$ in the $1960 \mathrm{~s}, 6.1 \%$ in 1987 , $7.92 \%$ in $2000,8.5 \%$ in 2004 and $11.1 \%$ in 2013 (24-27). This study found atopic dermatitis in $4.6 \%$ of patients, lower than recently documented from other centres (24-27). Some of the reasons propounded for the increase in prevalence of atopic dermatitis include increase awareness of eczematous disorders; fall in prevalence of infectious dermatoses; and the 'hygiene theory' as a result of the increase in Western diet and lifestyle and lower exposure to environmental antigens such as infections and bacteria endotoxins in childhood $(25,28)$.

The most common infection noted was fungal infections while the most predominant fungal infection was dermatophyte infections. The parts of the body affected by dermatophyte 
infections depend on the age of the individuals. Previous survey of dermatophyte infection at a skin clinic revealed that tinea capitis was seen in about $72 \%$ of dermatophyte in the first decade of life and rarely in adults reducing with increasing age, while tinea pedis, tinea unguium and tinea cruris peaked in the fourth decade; and tinea pedis was not documented in the first decade (29). The prevalence of onychomycosis has been shown to increase with advancing age with highest frequency in the elderly (30). Some of the factors found to be responsible for this include, poor peripheral circulation, diabetes mellitus (DM), repeated nail trauma, longer exposure to pathogenic fungi, sub optimal immune function, inactivity, inability to cut nails and to maintain good foot care $(30,31)$.

Apart from infections, infestations such as scabies, papular urticaria; and nutritional dermatoses such as phrynoderma were prominent mainly in the paediatric age group in this study (Table 1). A clinic based study reported a higher number of children with papular urticaria (14.6\%) and atopic dermatitis (13.8\%) compared to infections $(12.6 \%)(10)$. Contrary to this, community based studies in South West Nigeria found infectious dermatoses to be the most prevalent skin diseases, and very low or absent eczematous diseases. $(28,32)$

Impaired skin barrier function seen in infants and to a less extent in childhood has been implicated in infections in children $(7,8)$. In addition to the impairment in skin barrier function, the relatively low nutritional stores in newborns and children make them prone to nutritional deficiencies, with attendant skin manifestations. An interaction between the environment and the functional immaturity of the skin probably explains the high incidence of papular urticaria in this group (8-11). Papular urticaria affects children predominantly resulting from exaggerated response to insect bites and sting; more common during the summer in the temperate countries and all through the year in tropics when insect population increase (33). Heng suggested that papular urticaria is a result of cutaneous vasculitis (34). Papular urticaria is rare in adults as they are thought to outgrow it as a result of tolerance (33).

In the adolescent and young adults ( 17 to 25 years), acne vulgaris ranked first alongside with infections. Skin disorders were reported in $64.2 \%$ in an adolescent population and acne was the most prevalent dermatoses followed by pityriasis versicolor, nevi, tinea, milaria and keloid/hypertrophic scars (35). Acne vulgaris was documented in $90.7 \%$ of an adolescent population in Northern Nigeria with significant impact on their quality of life, while $64.2 \%$ was found in a similar study South West Nigeria (36,37). Amongst adolescent in Cameroun, acne vulgaris was found in $59.8 \%$ (38). The presence of testosterone may also initiate male-pattern baldness in adolescents (13).

The lowest frequencies of patients seen were in the elderly and middle age groups. This may be attributed to the fact that health care in Nigeria is still predominantly out of pocket and individuals in this group may not be able to afford care. Social circumstances such as poor nutrition, poor home care and lack of mobility; increasing dependence on others physically and financially may affect manifestation of skin disorders. Physiological problems such as dementia, a rigid attitude and refusal to accept help aggravate skin problems. (16-18) Similar to previous work done at this centre, infection was the most frequently seen dermatoses followed by eczemas, pruritus, pigmentary diseases and papulosquamous disorders (39). Some skin problems more common in old age due to the interplay of these factors include wrinkles, pruritus, xerosis and asteatotic eczema, infections and parasitoses, herpes zoster, ulcers and malignancies (15-18).

It is also important to note that while no specific structural changes has been demonstrated in menopausal skin; reduction in oestrogen receptors in the skin suggests that the withdrawal of oestrogen seen in menopause may be important. It is thus possible that certain features of menopausal skin such as dryness, epidermal thinning and loss of dermal elasticity may be due to the marked decrease in oestrogen levels (27).

A major limitation of this study is that it is hospital based and may not exactly represent the picture in the society. It however gives an indication of the most common reasons people visit the hospital. The prevalence amongst the elderly may also be under estimated as few of them will likely come to the hospital either because of the low economic status or presence of other life threatening co-morbidities such as heart failure and malignancies which will likely be given priority over cutaneous disorders.

\section{CONCLUSION}

This study noted that infections and eczematous condition were the most prominent group of cutaneous disorder across all ages apart 
from acne vulgaris which ranked high in the adolescents/young adults. Nutritional dermatoses, infestations and genetic disorders occurred predominantly in the pediatric age group. All other diseases peaked in the adult group whilst infections, eczemas and papulosquamous disorders had two peaks (in the pediatric and the adult age groups). The knowledge of pattern of skin disorders in different age groups will be useful in differential diagnoses, early and prompt management as well as inform the allocation of health resources in the resource limited setting. This will also be useful in the development of curriculae for medical undergraduates, postgraduate training in internal medicine, community and family medicine physicians and specialist residents in dermatology.

Conflict of interest: Authors declares no conflicts of interest.

\section{REFERENCES}

1. Balmanno S. The Influence of Age in the Causation of Skin-Disease. $B r$ Med $J$ 1873; 1(649): 641-642

2. Stamatas GN, Nikolovski J, Luedtke MA, Kollias N, Wiegand BC. Infant skin microstructure assessed in vivo differs from adult skin in organization and at the cellular level. Pediatr Dermatol 2010;27:125-131

3. Stamatas GN, Nikolovski J, Mack MC, Kollias $\mathrm{N}$. Infant skin physiology and development during the first years of life: a review of recent findings based on in vivo studies. Int $J$ Cosmet Sci 2011; 33(1): 17-24

4. Rogiers V. EEMCO guidance for the assessment of transepidermal water loss in cosmetic sciences. Skin Pharmacol Appl Skin Physiol 2001: 14: 117-128

5. Rutter N, Hull D. Water loss from the skin of term and preterm babies. Arch Dis Child 1979: 54: 858-868

6. Agren J, Sjors G, Sedin G. Ambient humidity influences the rate of skin barrier maturation in extremely preterm infants. J Pediatr 2006: 148 : 613-617

7. Firooz A, Sadr B, Babakoohi S, Sarraf-Yazdy M, Fanian F, Kazerouni-Timsar A et al. Variation of biophysical parameters of the skin with age, gender, and body region. Scientific World Journal 2012; 2012: 386936.

8. Yosipovitch G, Maayan-Metzger A, Merlob P, Sirota L et al. Skin barrier properties in different body areas in neonates. Pediatrics 2000; 106: 105-108

9. Emordi IJ, Ikefuna AN, Uchendu U, Duru UA. Skin diseases among children attending the outpatient clinic of the University of Nigeria teaching hospital, Enugu. Afr Health Sci 2010; 10(4): 362-366

10. Altraide DD, George IO, Frank-Briggs AI. Prevalence of skin diseases in Nigerian children - the University of Port Harcourt Teaching Hospital experience. Niger J Med 2008; 17(4): 417-419

11. El-Dawela RE, Fatehy AN, Elmoneim AA. Prevalence of skin diseases among school children: a survey in the Sohag Governorate. Journal of the Egyptian Women's Dermatologic Society 2012; 9(1):47-51

12. Sayal SK, Bal AS, Gupta CM. Pattern of skin diseases in paediatric age group and adolescents. Indian J Dermatol Venereol Leprol 1998; 64(3):117-119

13. Graham-Brown RAC. The Ages of Man and their dermatoses. In: Champion RH, Burton JL, Burns DA, Breathnach SM Eds. Rook/Wilkinson/Ebling Textbook of Dermatology $6^{\text {th }}$ ed. London: Blackwell Science Ltd. 1998; 3277-87

14. Halvorsen JA, Stern RS, Dalgard F, Thoresen M, Bjertness E, Lien L. Suicidal ideation, mental health problems, and social impairment are increased in adolescents with acne: a population-based study. J Invest Dermatol 2011; 131(2):363-370

15. Rothman S, Smiljanic A, Shapiro AL, Weitkamp AW. The spontaneous cure of tinea capitis at puberty. J Invest Dermatol 1947; 8: 81-98

16. Farage MA, Miller KW, Elsner P, Maibach HI. Characteristics of the Aging Skin. Adv Wound Care (New Rochelle) 2013; 2(1): 5-10

17. Farage MA, Miller KW, Berardesca E, Maibach HI. Clinical implications of aging skin: cutaneous disorders in the elderly. Am J Clin Dermatol 2009; 10(2):73-86

18. Montagna W, Carlisle K. Structural changes in ageing skin. Br J Dermatol 1990;122Suppl 35:61-70

19. Ogunbiyi OO, Daramola OOM, Alese OO. Prevalence of skin diseases in Ibadan, Nigeria. Int J Dermatol 2004; 43:31-36

20. Onayemi O, Isezuo SA, Njoku CH. Prevalence of different skin conditions in an outpatient's setting in North-West Nigeria. Int J Dermatol 2005; 44:7-11

21. Bissek AZ, Tabah EN, Kouotou E, Sini V, Yepnjio FN, Nditanchou R et al. The spectrum of skin diseases in a rural setting in Cameroon (subSaharan Africa). BMC Dermatology 2012; 12:7

22. Gibbs S. Skin disease and socioeconomic conditions in rural Africa: Tanzania. Int $J$ Dermatol 199; 35(9): 633-639

23. WHO. Epidemiology and Management of Common Skin Diseases in Children in Developing Countries. Department of Child and 
Adolescent Health and Development. 2005; $\mathrm{WHO} / \mathrm{FCH} / \mathrm{CAH} / 05.12$

24. Okoro OE, Sani H. Pattern of skin diseases at the dermatology clinic of Jos University Teaching Hospital, Jos Plateau State Nigeria. Jos Journal of Medicine 2014; 8 (2): 15-21

25. George AO. Atopic dermatitis in Nigeria. Int $J$ Dermatol 1989; 28(4): 237-239.

26. Onunu AN, Eze EU, Kubeyinje EP. Clinical profile of atopic dermatitis in Benin City, Nigeria. Niger J Clin Pract 2007; 10(4): 326329.

27. Nnoruka EN. Current epidemiology of atopic dermatitis in South-Eastern Nigeria. Int $J$ Dermatol 2004; 43(10): 739-744.

28. Ogunbiyi AO, Owoaje E, Ndahi A.Prevalence of skin disorders in school children in Ibadan, Nigeria. Pediatr Dermatol 2005; 22(1):6-10.

29. Ayanlowo OO, Akinkugbe AO. Overview of Dermatophyte infections at the Dermatology Outpatient Clinic of a Tertiary Institution in Nigeria. Nig QJ Hosp Med 2013; 23:1-6.

30. Elewski BE, Charif MA. Prevalence of onychomycosis in patients attending a dermatology clinic in northeastern Ohio for other conditions. Arch Dermatol 1977; 133:1172-1173.

31. Pierard G. Onychomycosis and other superficial infections of the foot in the elderly: a panEuropean survey. Dermatol 2001: 202:220-224

32. Akinkugbe AO, Amira OC, Ozoh OB, Fasanmade O, Bandele E. Pattern of skin disorders in a rural community in Southwest Nigeria. The Nigerian Health Journal 2016; 16 (2): 103-116

33. Demain JG. Papular urticaria and thins that bite in the night. Curr Allergy Asthma Rep. 2003;3:291-303

34. Heng MC, Kloss SG, Haberfelde GC. Pathogenesis of papular urticaria. J Am Acad Dermatol 1984; 10(6):1030-1034.

35. Henshaw EB, Olasode OA, Ogedegbe EE, Etuk I. Dermatologic conditions in teenage adolescents in Nigeria. Adolesc Health Med Ther 2014; 5: 79-87.

36. Yahya H. Acne vulgaris in Nigerian adolescents-prevalence, severity, beliefs, perceptions, and practices. Int J Dermatol 2009; 48(5): 498-505.

37. Okoro E, Ogunbiyi A, George A. Prevalence and pattern of acne vulgaris among adolescents in Ibadan, south-west Nigeria. Journal of the Egyptian Women's Dermatologic Society 2016; $13(1): 7-12$

38. Mbuagbaw J, Abongwa C, Ozoh G, Blackett K. The Prevalence of Acne Vulgaris In Secondary School Students In Yaoundé, Cameroon. The Internet Journal of Dermatology 2006; 5 (2):1-4

39. Ayanlowo OO, Akinkugbe AO, Olumide YM, Ahamneze N. Dermatoses In The Elderly At The Dermatology Clinic Of The Lagos University Teaching Hospital. Nig J Dermatol 2011; 1: 1016.

Res. J. of Health Sci. Vol 5(3), July/Sept. 2017
40. Wines N, Willsteed E. Menopause and the skin. Austral J Dermatol 2001; 42: 149-60 


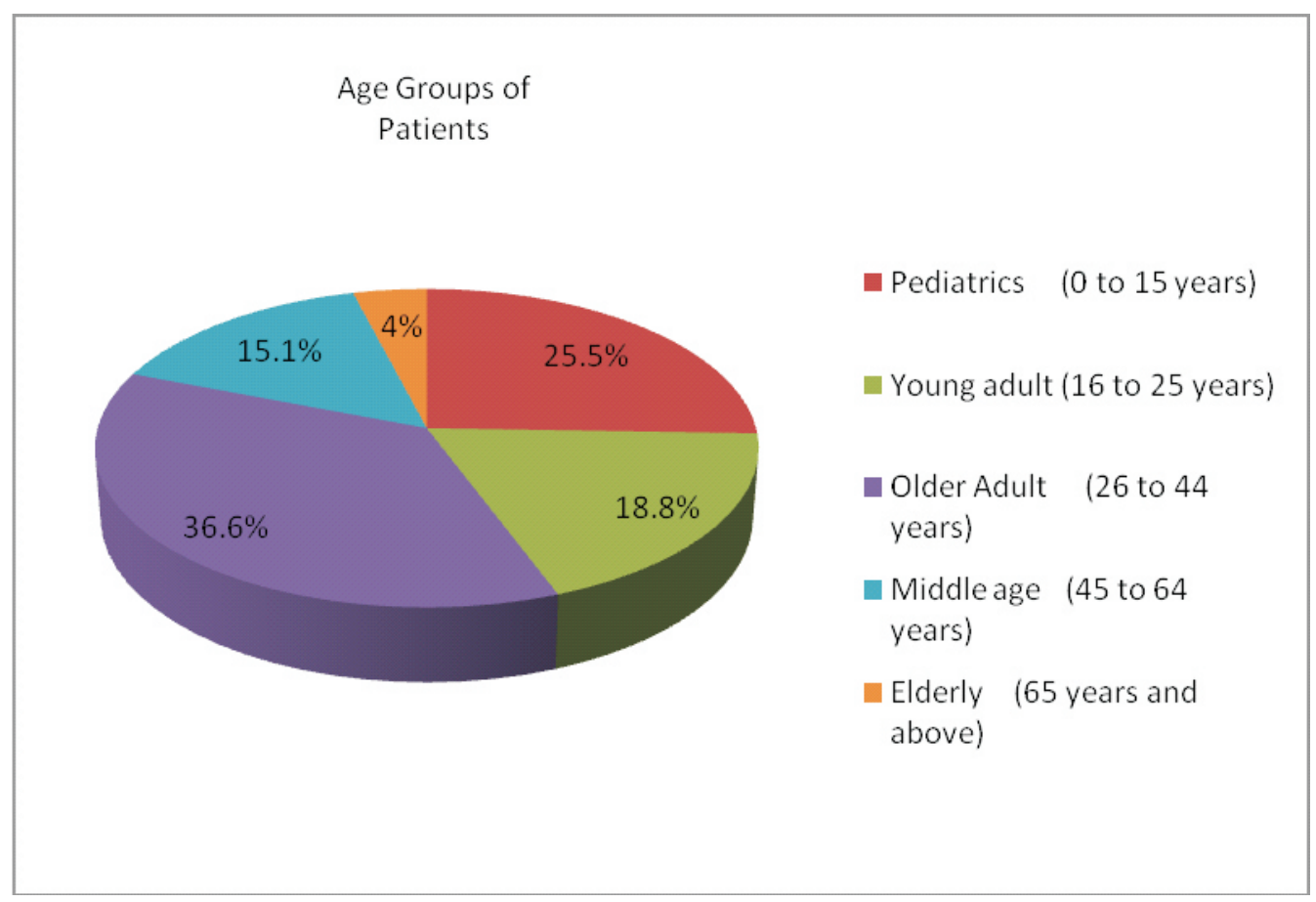

Figure 1: Frequency of patients in Different Age Groups

Table 1: Frequency of Skin Disorders According to Age Groups

\begin{tabular}{llllllll}
\cline { 2 - 7 } Disease group & Paediatrics & $\begin{array}{l}\text { Young } \\
\text { Adult }\end{array}$ & Adult & $\begin{array}{l}\text { Middle } \\
\text { Age }\end{array}$ & Elderly & Total (\%) & $\begin{array}{l}\text { Mean age at } \\
\text { presentation }\end{array}$ \\
\cline { 2 - 7 } Infections & 779 & 495 & 1110 & 495 & 138 & $3017(25.87)$ & $29.62 \pm 18.51$ \\
Eczemas & 652 & 273 & 582 & 236 & 76 & $1819(15.59)$ & $25.67 \pm 19.48$ \\
Pruritic Dermatoses & 83 & 175 & 446 & 249 & 49 & $1002(8.59)$ & $36.27 \pm 16.31$ \\
Acne and Rosacea & 58 & 495 & 407 & 36 & 3 & $999(8.56)$ & $25.61 \pm 8.58$ \\
Papulosquamous & 241 & 161 & 307 & 171 & 33 & $913(7.83)$ & $29.81 \pm 17.86$ \\
Pigmentary & 133 & 125 & 254 & 140 & 39 & $691(5.92)$ & $32.59 \pm 18.35$ \\
Infestations & 397 & 106 & 105 & 40 & 13 & $661(5.67)$ & $16.50 \pm 16.66$ \\
Scars & 57 & 126 & 219 & 57 & 20 & $479(4.11)$ & $31.05 \pm 15.66$ \\
Tumors & 38 & 57 & 164 & 100 & 27 & $386(3.31)$ & $37.27 \pm 17.35$ \\
Alopecias & 40 & 84 & 224 & 32 & 3 & $383(3.28)$ & $29.95 \pm 11.95$ \\
Drugs & 26 & 45 & 106 & 32 & 9 & $218(1.87)$ & $32.39 \pm 15.87$ \\
CTD & 15 & 33 & 99 & 49 & 16 & $212(1.82)$ & $37.10 \pm 16.48$ \\
Genetic diseases & 89 & 45 & 44 & 10 & 1 & $189(1.62)$ & $18.75 \pm 15.28$ \\
Bullous disorders & 83 & 33 & 24 & 16 & 3 & $159(1.36)$ & $20.24 \pm 15.81$ \\
Granulomas & 31 & 15 & 41 & 18 & 3 & $108(0.93)$ & $27.90 \pm 18.10$ \\
Lymphoedemas & 11 & 14 & 29 & 21 & 8 & $83(0.71)$ & $37.88 \pm 18.95$ \\
Xerosis & 18 & 9 & 20 & 16 & 13 & $76(0.65)$ & $37.03 \pm 24.98$ \\
Ulcers & 3 & 7 & 27 & 15 & 5 & $57(0.49)$ & $39.77 \pm 16.64$ \\
Psychocutaneous & 4 & 4 & 10 & 9 & 3 & $30(0.26)$ & $39.43 \pm 20.06$ \\
Nutritional & 26 & 0 & 2 & 0 & 0 & $28(0.24)$ & $8.64 \pm 7.79$ \\
Miscellaneous & 16 & 24 & 68 & 28 & 18 & $154(1.32)$ & $36.82 \pm 18.70$ \\
Total & 2800 & 2326 & 4288 & 1770 & 480 & $11664(100)$ & \\
& & & & & & &
\end{tabular}

CTD Connective tissue Disorders 
Table 2: Frequency of Eczemas, Xerosis, Pruritus and Related Dermatoses

\begin{tabular}{|c|c|c|}
\hline Types of Eczemas & Frequency (n) & Percentage (\%) \\
\hline Atopic dermatitis & 537 & 4.60 \\
\hline Seborrhoeic dermatitis & 496 & 4.25 \\
\hline Contact dermatitis & 283 & 2.43 \\
\hline Folliculitis & 140 & 1.20 \\
\hline Erythroderma & 133 & 1.14 \\
\hline Stasis dermatitis & 46 & 0.39 \\
\hline Sycosis cruris & 38 & 0.33 \\
\hline Chronic dermatitis & 36 & 0.31 \\
\hline Keratosis pilaris & 22 & 0.19 \\
\hline Acute dermatitis & 16 & 0.14 \\
\hline Photodermatitis & 16 & 0.14 \\
\hline Nummular eczema & 12 & 0.10 \\
\hline Pityriasis alba & 8 & 0.07 \\
\hline Dyshydrotic eczema & 7 & 0.06 \\
\hline Lichen striatus & 7 & 0.06 \\
\hline *Others & 22 & 0.19 \\
\hline \multicolumn{3}{|c|}{ Pruritus and Related Dermatoses } \\
\hline Urticaria/angioedema & 421 & 3.61 \\
\hline Generalised pruritus/pruritus & 205 & 1.76 \\
\hline Lichen simplex chronicus & 202 & 1.73 \\
\hline Pruritic papular eruption & 72 & 0.62 \\
\hline Prurigo nodules & 54 & 0.46 \\
\hline Aquagenic pruritus & 22 & 0.19 \\
\hline Mastocytosis & 16 & 0.14 \\
\hline Senile pruritus & 9 & 0.08 \\
\hline Drug induced pruritus & 1 & 0.01 \\
\hline \multicolumn{3}{|l|}{ Xerotic Disorders } \\
\hline Ichthyosis vulgaris & 45 & 0.39 \\
\hline Generalised Xerosis & 20 & 0.17 \\
\hline Senile xerosis & 11 & 0.09 \\
\hline
\end{tabular}

*Other eczematous conditions include acropapular dermatitis 5, Pompholyx 5 , Gianotti Crosti Syndrome 3, infective dermatitis 6, post steroid dermatitis 1, frictional dermatitis 1 , granulomatous cheilitis 1 , diabetic dermopathy 1

Table 3: Infections and Infestations

\begin{tabular}{lll}
\hline Infections & Frequency (n) & Percentage \% \\
\hline Fungal Infections & $\mathbf{2 1 2 0}$ & $\mathbf{1 8 . 0 2}$ \\
- Dermatophytes & 1549 & 13.28 \\
- Pityriasis versicolor & 360 & 3.09 \\
- Candidiasis & 197 & 1.69 \\
- Deep mycosis & 7 & 0.06 \\
- Mixed fungal infections & 7 & 0.06 \\
Viral Infections & $\mathbf{5 9 4}$ & $\mathbf{5 . 0 9}$ \\
- Verrucae/warts & 331 & 2.84 \\
- Molluscum contagiosum & 105 & 0.90 \\
- Epidemodysplasia & 59 & 0.51 \\
- Herpes simplex & 42 & 0.36 \\
- Herpes zoster & 32 & 0.27 \\
- Viral exanthema & 17 & 0.15 \\
- Retroviral disease & 4 & 0.03 \\
- Chicken pox & 4 & 0.03 \\
Bacterial & $\mathbf{3 0 2}$ & $\mathbf{2 . 5 9}$ \\
Hansens & 131 & 1.12 \\
Periporitis & 41 & 0.35 \\
Impetigo Contagiosum & 33 & 0.28 \\
Cellulitis & 25 & 0.21 \\
Cutaneous tuberculosis lesions & 24 & 0.21 \\
Secondary bacteria & 18 & 0.15 \\
Furuncle & 13 & 0.11 \\
*Other bacterial infections & 17 & 0.15 \\
Infestation & & 3.68 \\
Papular urticaria & 429 & 1.09 \\
Onchodermatitis \& Other filariasis & 127 & 0.43 \\
Dermodex folliculitis & 50 & 0.33 \\
Scabies & 38 & 0.15 \\
**Others & 17 & \\
\cline { 2 - 3 } & & \\
& &
\end{tabular}

*Other bacterial infections include osteomyelitis 6, pitted keratolysis 4, ecthyma 2 , impetiginisation of existing skin disorders

**Other Infestations include insect bite 7, leishmaniasis 3, cutaneous larva migrans 2 , bed bug 2 , pediculosis 1 , blister beetle 1 , helminthiasis 1 
Table 4: Bullous, papulosquamous and Connective tissue Disorders

\begin{tabular}{lll}
\hline Bullous Skin Disorders & Frequency (n) & Percentage (\%) \\
\hline Chronic bullous dermatitis of childhood & 102 & 0.87 \\
Immunobullous & 37 & 0.32 \\
Congenital bullous Ichthyosiform erythroderma & 5 & 0.04 \\
Dermatitis herpetiformis & 4 & 0.03 \\
*Others & 11 & 0.09 \\
Papulosquamous Disorders & & \\
Lichen planus & 349 & 2.99 \\
Psoriasis & 263 & 2.25 \\
Pityriasis rosea & 170 & 1.46 \\
Lichen nitidus & 65 & 0.56 \\
Pityriasis lichenoides chronic & 48 & 0.41 \\
Lichen striatus & 7 & 0.06 \\
**Others & 11 & 0.09 \\
Connective Tissue Disorders & & \\
Systemic lupus erythematous & 98 & 0.84 \\
Scleroderma & 39 & 0.33 \\
Rheumatoid arthritis & 15 & 0.13 \\
Osteoarthritis & 10 & 0.09 \\
Panniculitis & 6 & 0.05 \\
Juvenile idiopathic arthritis & 5 & 0.04 \\
Vasculitis & 4 & 0.03 \\
Mixed connective tissue disease & 4 & 0.03 \\
$* * *$ Others & 32 & 0.27 \\
\cline { 2 - 3 } & &
\end{tabular}

*Other bullous diseases include erythema multiforme 3, bullous impetigo 3, Grover's disease 1 , Dariers 1, undetermined cause 3

**Other papulosquamous disorders include unspecified 6, lichen amyloidosis 1, Pityriasis amiantacea 1, Pityriasis Rubra pilaris 3

***Others include arthritis of undetermined aetiology 11, inflammatory polyarthritis 4, Behcet's disease 3, antiphospholipid syndrome 3, fibromyalgia 2, spondyloarthropathy 2, dermatomyositis 2 , gout 1 , chronic fatigue syndrome 1 , spondylosis 1 , bunion 1

Table 5: Tumours and Genetic Disorders

\begin{tabular}{lll}
\hline & Frequency(n) & Percentage (\%) \\
\hline Benign & $\mathbf{2 9 6}$ & 2.54 \\
Dermatosis papulosa nigra & 84 & 0.72 \\
Syringoma & 66 & 0.57 \\
Steatocytoma & 34 & 0.29 \\
Miliaria & 27 & 0.23 \\
Acrocordion & 22 & 0.19 \\
Lipoma & 15 & 0.13 \\
Xanthomas & 12 & 0.10 \\
Trichoepithelioma & 9 & 0.08 \\
Dermatomyofibroma & 7 & 0.06 \\
*Others & 20 & 0.17 \\
Malignant & $\mathbf{9 0}$ & $\mathbf{0 . 7 7}$ \\
- Kaposi's sarcoma & 54 & 0.46 \\
- Basal cell carcinoma & 12 & 0.10 \\
- Lymphomas & 7 & 0.06 \\
- Malignant Melanoma & 6 & 0.05 \\
- Squamous cell carcinoma & 3 & 0.03 \\
- **Others & 8 & 0.07 \\
Genetic Disorders & $\mathbf{1 8 9}$ & 1.62 \\
Neurofibromalosis & 83 & 0.71 \\
Nevus & 71 & 0.61 \\
Hemangioma & 23 & 0.20 \\
Tuberous scleross & 7 & 0.06 \\
***Others & 8 & 0.07 \\
\hline
\end{tabular}

*Other benign tumors include lymphangioma circumscriptum 3, eyelid tumors 2 , trichofoliculoma 2 , chondrodermatitis helicis 2 , ganglion 1 , lymphomatoid papulosis 1 , sebaceous adenoma 1 , pseudo epitheliomatous hyperplasia 1

**Other malignant tumors include internal malignancies 5, malignant transformation of pseudo epitheliomatous hyperplasia 1, Paget's disease of the breast 1

***Others genetic disorders include acanthosis nigricans 4 , angioma 1 , ichthyosis 1 , portwine wine stain 1 , pseudoxanthoma elasticum 1 
Table 6: Alopecias and Pigmentary Disorders

\begin{tabular}{lll}
\hline Dermatoses & Frequency (n) & Percentage (\%) \\
\hline Alopecias & $\mathbf{3 8 3}$ & $\mathbf{3 . 2 8}$ \\
Acne Keloidalis nuchae/acne folliculitis nuchae & 167 & 1.43 \\
Alopecia areata & 101 & 0.87 \\
Folliculitis decalvans & 22 & 0.19 \\
Dissecting folliculitis/cellulitis & 20 & 0.17 \\
Folliculitis barbae & 15 & 0.13 \\
Traction alopecia & 10 & 0.09 \\
Androgenetic alopecia & 6 & 0.05 \\
*Scarring alopecia (undetermined cause) & 12 & 0.10 \\
*Non scarring alopecia (undetermined cause) & 20 & 0.17 \\
Others & 12 & 0.10 \\
Pigmentary Disorders & $\mathbf{6 9 1}$ & $\mathbf{5 . 9 2}$ \\
Vitiligo & 310 & 2.66 \\
Post - inflammatory hyperpigmentation & 117 & 1.00 \\
Albinism & 24 & 0.21 \\
Dyschromia from bleaching & 92 & 0.79 \\
Exogenous ochronosis & 64 & 0.55 \\
Idiopathic guttate hypomelanosis & 28 & 0.24 \\
Diffuse pigmentation & 17 & 0.15 \\
Post - inflammatory hypopigmentation & 13 & 0.11 \\
Photoaging & 6 & 0.05 \\
**Others & 21 & 0.18 \\
\hline & &
\end{tabular}

Others include discoid lupus erythematosus 4, chemical alopecia 3, Pityriasis amiantacea 1, central centrifugal cicatricial alopecia 1

* Specific aetiologic of alopecia not determined

**Conditions in pigmentary disorders designated others are Melasma 5, photodermatosis 5 ,

pot inflammatory depigmentation 5 , Nail pigmentation 4 , incontinenti pigmenti 1 , tattoo 1 